\title{
Infecção em humanos por varíola bovina na microrregião de Itajubá, Estado de Minas Gerais: relato de caso
}

\author{
Human infection by the cowpox virus in the microregion \\ of Itajubá, State of Minas Gerais: case report
}

\begin{abstract}
Afonso Carlos da Silva ${ }^{1}$, Bruno Borges Reis ${ }^{1}$, José Eugênio Rios Ricci Junior ${ }^{1}$, Fabiana Sirolli Fernandes ${ }^{1}$, José Fabio Corrêa ${ }^{2}$ e Hermann G. Schatzmayr ${ }^{3}$
\end{abstract}

\begin{abstract}
RESUMO
Os autores relatam três casos de varíola bovina em humanos, ordenhadores manuais em vacas infectadas, na microrregião de Itajubá, MG. As técnicas diagnósticas foram: isolamento de amostra semelhante ao vírus vaccinia de secreções das lesões cutâneas, reação em cadeia de polimerase, microscopia eletrônica e anticorpos para Orthopoxvirus no sangue dos pacientes.
\end{abstract}

Palavras chaves: Varíola bovina. Vaccinia virus. Orthopoxvirus.

\section{ABSTRACT}

The authors report three human cases of cowpox infection, among farm workers who were manually milking infected cows, in the microregion of Itajubá, Minas Gerais. The diagnostic techniques used were: isolation of samples similar to the vaccinia virus, from skin lesion secretions; polymerase chain reaction; electronic microscopy; and antibodies for Orthopoxvirus in the patients' blood.

Key-words: Cowpox. Vaccinia virus. Orthopoxvirus.

A varíola bovina é zoonose causada pela proliferação de vírus do gênero Orthopoxvirus. Caracteriza-se por lesões papulares que evoluem para vesículas, pústulas e crostas. Dentro do gênero Orthopoxvirus conhece-se os vírus cowpox e vaccínia. 0 vírus cowpox circula na Europa e Oriente Médio sendo responsável por infecções em roedores, animais domésticos como o gato e em bovinos, nos quais causam a redução da produção de leite. 0 vírus vaccínia foi utilizado no passado para o preparo da vacina contra a varíola humana, doença grave erradicada na década de 70. Este último é o responsável pelos recentes surtos ocorridos no $\mathrm{Brasil}^{78}$.

A partir do final da década de 90, propriedades rurais de Minas Gerais, São Paulo, Rio de Janeiro e Goiás, foram atingidas por surtos epizoóticos de varíola bovina, causadas pelo vírus vaccinia, acometendo animais e humanos. Esses surtos acarretaram grandes prejuízos principalmente pela diminuição na produção de leite por mastite e contaminações bacterianas secundárias nos úberes das vacas e pelos quadros clínicos em ordenhadores 3791216 .
Em pesquisas envolvendo estes surtos descobriu-se que a transmissão entre os animais ocorria principalmente através das mãos dos ordenhadores ou equipamentos de ordenha mecânica e a penetração dos vírus ocorria por soluções de continuidade presentes nas tetas das vacas. A contaminação humana pela doença ocorre pelo contato com as lesões presentes nos animais sendo, portanto, mais comum em trabalhadores rurais, especificamente ordenhadores que não utilizam proteção individual e adquirem os vírus por meio de lesões e microabrasões na pele ${ }^{47}$.

0 objetivo deste estudo é descrever três casos de infecção em humanos por varíola bovina, visto que, esta patologia está se disseminando em nosso meio e, desta forma, aumentando sua incidência. Procuramos então contribuir para seu conhecimento e esclarecimento a fim de que médicos e profissionais de saúde estejam cientes e aptos a abordarem a moléstia, contribuindo para seu controle, principalmente em nossa região.

Descrição dos casos estudados. São descritos três casos de contaminação pela varíola bovina em humanos, provenientes de áreas rurais diferentes pertencentes à microrregião da Cidade de

\footnotetext{
1. Departamento de Clínica Médica, Faculdade de Medicina de Itajubá, Itajubá, MG. 2. Setor de Doenças Infecto-Contagiosas, Faculdade de Medicina de Itajubá, Itajubá, MG 3. Instituto Oswaldo Cruz, Grupo de Poxvirus, Laboratório de Hantavirus, Rio de Janeiro, RJ.

Endereço para correspondência: Dr. Afonso Carlos da Silva. R. Maria Mauad Galhardo 71, Bairro Morro Chic, 13500-096 Itajubá, MG.

Tel.: $55353623-4347$

e-mail: afonsogh@uol.com.br

Recebido para publicação em 12/06/2008

Aceito em 16/09/2008
} 
Itajubá, Minas Gerais, sendo dois casos da mesma família, brancos, do sexo masculino, ordenhadores, com idade compreendida entre 28 e 50 anos, que procuraram, espontaneamente, o serviço de urgência do Hospital Escola da Faculdade de Medicina de Itajubá, Minas Gerais (HE-FMIt/MG) no período de outubro a novembro de 2007. Todos apresentavam lesões vesico-bolhosas que evoluíram para crostas com infecção secundária, inicialmente nas mãos e antebraços (Figura 1). Dois deles apresentavam também lesões em regiões periorbitária e vestíbulo nasal (Figura 2). Relatavam em comum fazerem ordenha manual, não usarem medidas de proteção e de terem contato direto com as tetas e úberes de vacas que apresentavam lesões ulceradas (Figura 3). 0 quadro clínico dos pacientes era de toxemia com queda no estado geral, sinais de desidratação, anorexia, febre alta, mialgia e artralgia. Os que apresentaram lesão facial possuíam adenomegalia cervical anterior, com gânglios dolorosos à palpação sugestivos de adenomegalia reacional. Dois pacientes, devido ao maior grau de comprometimento do estado geral, pela toxemia e desidratação, foram internados na enfermaria de Clínica Médica do mesmo hospital e submetidos ao tratamento das lesões

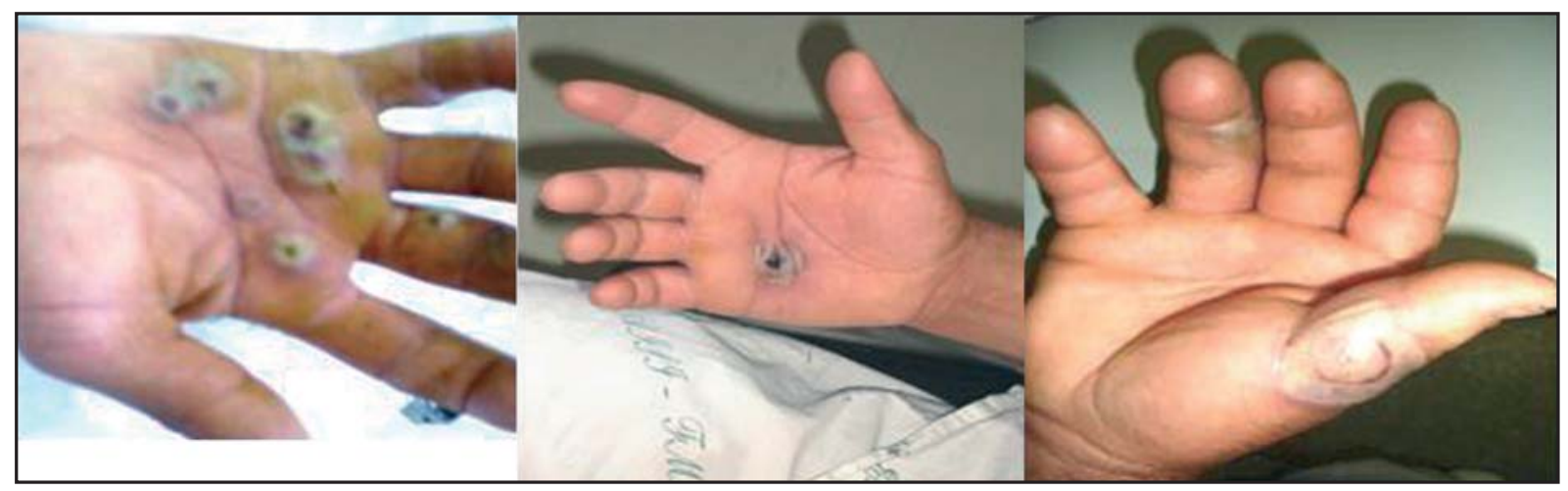

Figura 1 - Lesão nos dedos e face palmar dos ordenhadores.

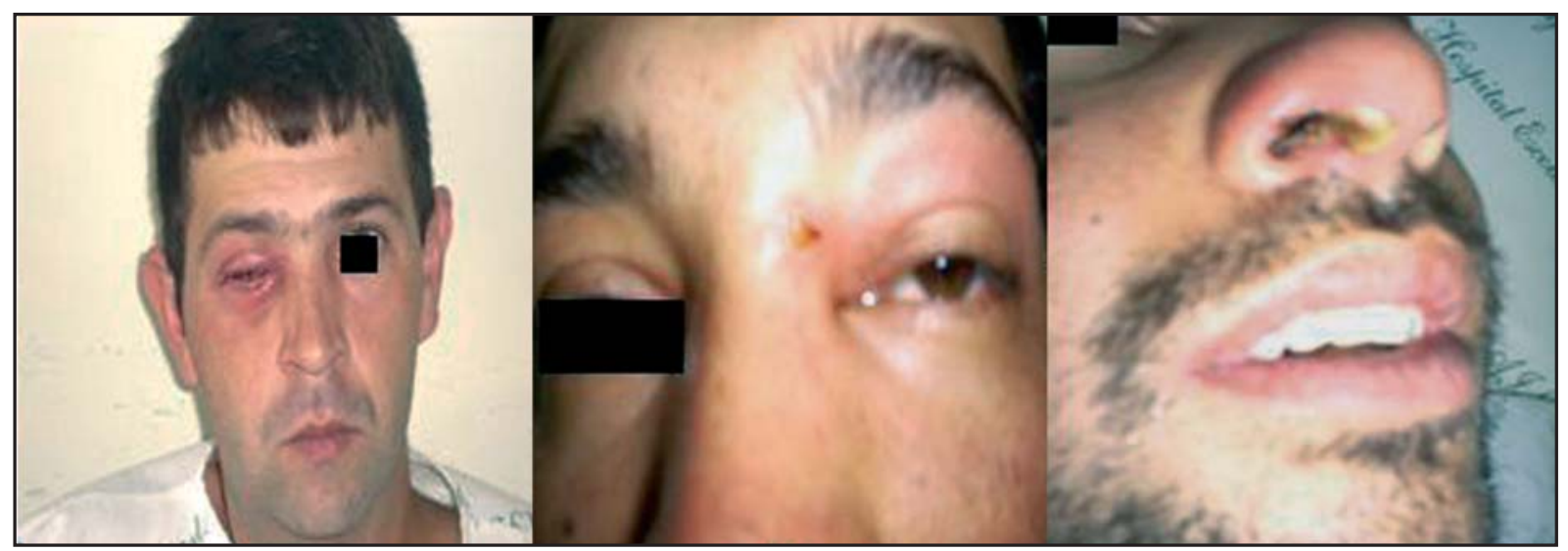

Figura 2 - Lesão em vestíbulo nasal, periorbitaria e intraorbitaria pelo Vaccinia vírus.

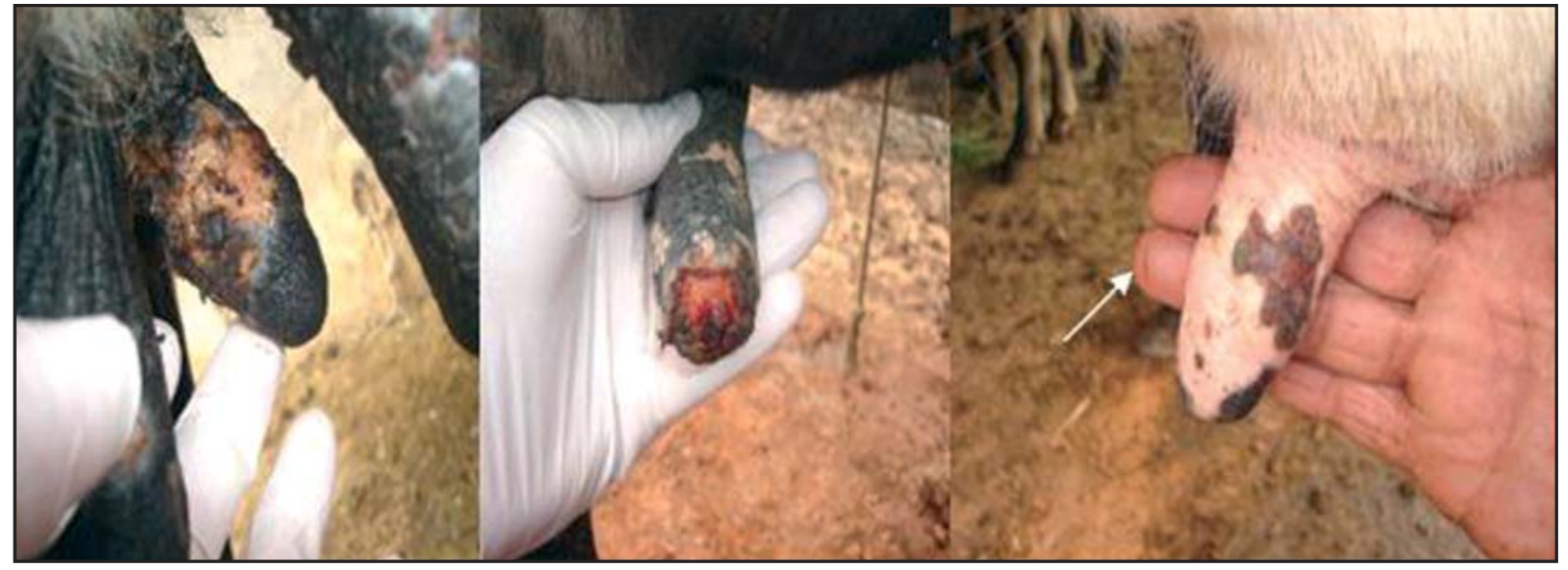

Figura 3 - Lesões ulceradas em tetas de vacas contaminadas por Varíola bovina. Note a solução de continuidade no dedo anular na mão do ordenbador. 
cutâneas com medidas locais, antibioticoterapia sistêmica devido à contaminação bacteriana nas lesões, e hidratação venosa.

Foram submetidos ainda a exames laboratoriais como hemograma, bioquímica básica, com bacterioscopia, cultura e antibiograma da secreção das vesículas, sendo isolado 0 Staphylococus aureus como agente bacteriano contaminante secundário das lesões cutâneas. Amostras por coleta de secreção das vesículas, fragmentos das crostas e soro dos pacientes foram enviados para o Departamento de Virologia da Fundação Ezequiel Dias (FUNED) em Belo Horizonte, MG, e depois para a Fundação Oswaldo Cruz (FIOCRUZ) no Rio de Janeiro, RJ.

Todos os pacientes apresentaram resolução completa do quadro clínico após um mês do início dos sintomas. Fizeram controle no ambulatório de Clinica Médica do HE-FMIt até 0 resultado dos exames enviados para estudo nas Fundações acima citadas e depois liberados.

Diagnóstico laboratorial. A etiologia dos casos acima descritos, foi confirmada pela FIOCRUZ, por microscopia eletrônica de macerados dos espécimes clínicos enviados para estudo, sendo feita uma contrastação negativa com ácido fosfotungstico a $2 \%$ para visualizar as estruturas características dos Orthopoxvirus (Figura 4).

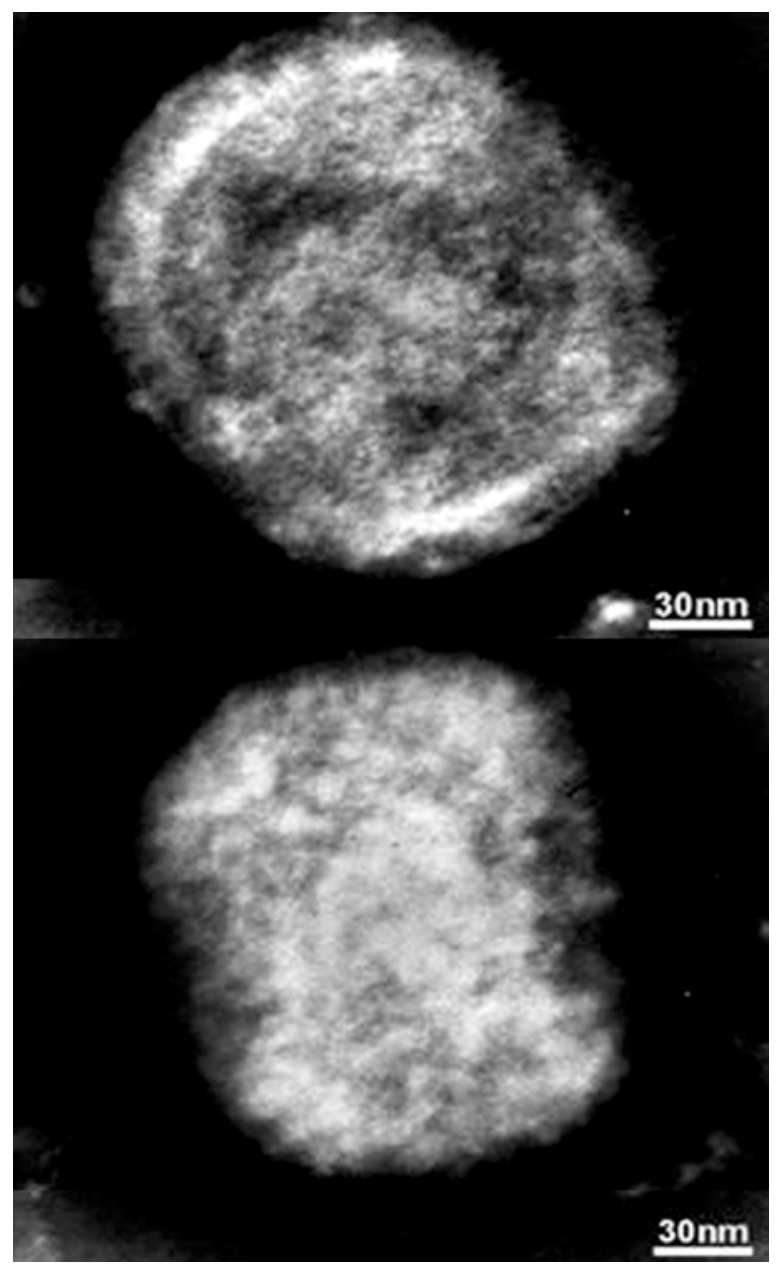

Figura 4 - Foto do Vaccinia vírus obtida por Microscopia Eletrônica (ME) de material coletado do macerado das lesões (FIOCRUZ).
Os macerados foram ainda inoculados em uma linhagem de células Vero para isolamento viral e para prova molecular de PCR, com primers específicos para o vaccinia virus, a qual demonstrou a presença de acido nucléico viral do vírus vaccínia.

Para determinação de anticorpos os soros dos pacientes foram diluídos a partir de 1/10 e incubados com uma suspensão de vírus da amostra Cantagalo de Orthopoxvirus. Após uma hora a $37^{\circ} \mathrm{C}$ as misturas soro e vírus foram distribuídas em microplacas de fundo chato e a suspensão de células adicionada a cada cavidade da placa. A leitura foi feita com 48 horas por método de redução de $50 \%$ do número de placas formadas em presença das diluições de soro e nos controles virais, após coloração com cristal violeta.

\section{DISCUSSÃO}

No homem, as lesões por Orthopoxvirus surgem de cinco a sete dias após o contato, localizando-se nos membros superiores, principalmente nas mãos. Caracterizam-se, inicialmente por máculas pruriginosas que evoluem para pápulas e pústulas, muito dolorosas, até a formação de crostas. Pode haver a disseminação do vírus para a mucosa ocular através do contato direto, sob o risco de desenvolvimento de cegueira. Frente a este quadro outras hipóteses devem ser consideradas, ou seja, faz-se diagnóstico diferencial com impetigo bolhoso, erisipela, doença da arranhadura do gato $\mathrm{e}$ $\operatorname{antrax}^{1113}$. A doença é geralmente benigna, de curso autolimitado, resolvendo-se em até quatro semanas ${ }^{4813}$.

As lesões de tetas e úberes dos bovinos são geralmente vesiculares, provocadas por diversos vírus, sendo mais freqüentes por vírus cowpox, vaccinia, herpes e a papilomatose ${ }^{15}$.

0 último caso de varíola humana ocorreu na Somália, em 1977, e a doença foi considerada erradicada pela OMS em 1980. Como resultado, a imunização em massa com o Vaccinia virus foi descontinuada, permitindo um declínio da imunidade ao gênero Orthopoxvirus e resultando em um aumento de infecções por Orthopoxvirus em humanos ${ }^{17}$.

Os primeiros relatos na literatura abordando surtos de varíola bovina no Brasil são datados das décadas de 50 a 70 , envolvendo estados da região sudeste. Até meados dos anos 80 os casos ocorriam mais esporadicamente, com intervalos de até 10 anos entre os surtos. Este cenário mudou nos anos subseqüentes, em vista da ocorrência mais freqüente de varíola bovina, abrangendo os Estados de Goiás e Mato Grosso, além de municípios do Vale do Paraíba (SP), Zona da Mata (MG) e na região do noroeste (RJ) $)^{89} 15$ Nas regiões da Europa em que circula o vírus cowpox, na maior parte dos casos relatados em humanos, o contato com gatos é a principal fonte de infecçã $0^{1}$. Acredita-se que os reservatórios naturais destes vírus sejam roedores que os transmitem para vacas, gatos, animais de zoológicos e $\operatorname{circos}^{1217}$. Em raros relatos, 0 vírus foi contraído diretamente de $\operatorname{ratos}^{61017}$.

No Brasil, os trabalhos elucidam o contato com lesões em tetas e úberes de vacas como sendo o sítio de contaminação mais frequiente e, com raras exceções, os trabalhadores rurais contaminados negam tal contat $0^{89}$. 
Através de técnicas de isolamento viral, pode-se comprovar que os surtos no Brasil são devidos ao vírus vaccínia, originário muito provavelmente de amostras do mesmo vírus que foram utilizadas para o preparo de vacinas ${ }^{813}$, diferentemente do que ocorre na Europa, com relatos de varíola bovina por cowpox ${ }^{8}{ }^{12}$. Esta hipótese foi sustentada pela análise molecular dos vírus isolados nos municípios de Araçatuba (SP) e Cantagalo (RJ), observando-se semelhanças com o vírus vaccinia de origem animal.

A partir de então, foi aventado a hipótese de que a amostra vacinal teria sido mantida na natureza, estabelecendo ciclos de transmissão em algum animal silvestre ainda indeterminado, que poderia estar transmitindo o vírus para as vacas e essas para os ordenhadores ${ }^{3816}$.

Dentre as várias espécies virais, as lesões causadas pelos vírus vaccinia e cowpox são bastante semelhantes entre si e difíceis de se diferenciar clinicamente ${ }^{8}$.

As lesões típicas pela infecção do vírus do gênero Orthopoxvírus são caracterizadas por pápulas que evoluem para vesículas, podendo as mesmas formar conteúdo hemorrágico antes de ulcerarem, esta última mais tipicamente relacionada à espécie cowpox $^{12} 1314$. Em poucos dias, tornam-se crostas e cicatrizam por completo após algumas semanas. A área adjacente das lesões é rica em sinais flogísticos e em sintomas constitucionais como febre, mal-estar, artralgia, mialgia, além de linfoadenopatia ${ }^{14}$. Os pacientes deste relato de caso referiam todos os sinais e sintomas acima e queixavam-se, principalmente, de dor nas lesões cutâneas.

Não é necessário um tratamento específico da varíola bovina em humanos, pois se trata de uma doença autolimitada na maioria dos casos, devendo-se realizar medidas de limpeza e higiene local. Tratamento sintomático e antibioticoterapia nos casos de infecção bacteriana secundária são indicados, quando presentes ${ }^{12} 14$. Corticosteróides são contra-indicados por agravarem as lesões 5 . Nos pacientes que desenvolvem a forma disseminada e mais grave da doença, normalmente indivíduos atópicos ou imunossuprimidos, a vaccinia imunoglobulina pode ser administrada. 0 uso do antiviral cidoforvir vem sendo utilizado com sucesso em modelos animais infectados com o vírus cowpox, mas ainda não é indicado em humanos devido ao seu alto potencial tóxico, em especial no sistema urinário ${ }^{510}$.

Concluindo, o número de casos de varíola bovina em seres humanos vem aumentando a cada ano. Contudo, apenas uma fração vem sendo demonstrada nos trabalhos publicados sobre este tema no Brasil. A maior parte dos pacientes infectados são trabalhadores rurais que normalmente não procuram serviço médico por tratar-se de uma doença autolimitada, ou quando 0 fazem, são na sua grande maioria subdiagnosticados sendo os casos suspeitos não investigados e muito menos notificados.

Nos últimos anos, tem-se observado aumento significativo de surtos de varíola bovina em diferentes estados brasileiros ${ }^{3489}$.Em particular, devemos nos preocupar com o crescente número de casos no Estado de Minas Gerais pelo seu forte potencial leiteiro. Informações com aspectos epidemiológicos da doença devem ser relatados para sua rápida detecção e identificação viral com 0 intuito de evitar a sua disseminação. Será importante determinar que animais mantêm o vírus na natureza, pois bovinos e humanos devem ser hospedeiros acidentais.

Campanhas de esclarecimento sobre a varíola bovina nas áreas rurais, principalmente para os ordenhadores, focando os meios de contaminação da doença, medidas de prevenção e cuidados com os animais doentes devem ser incentivadas.

Os profissionais de saúde, em especial os médicos, devem ser orientados sobre a doença e estar atentos para o diagnóstico desta infecção, evitando-se assim subdiagnósticos e tratamentos desnecessários.

Todos os casos suspeitos deveriam ser notificados compulsoriamente nas regiões onde, sabidamente, já existem focos da doença. As secretarias de saúde nestas cidades seriam então orientadas para que mandassem o material de casos suspeitos para laboratórios de referência no próprio estado com a finalidade de agilizar o diagnóstico e rapidamente conseguir traçar um mapa da doença na região visando o seu controle.

\section{AGRADECIMENTOS}

Agradecemos à valiosa colaboração da Drª Simone Berger Calic da Fundação Ezequiel Dias (FUNED), Belo Horizonte-MG, aos Pesquisadores da Fundação Oswaldo Cruz, Rio de Janeiro-RJ, em nome do Prof. Hermann G. Schatzmayr e principalmente aos pacientes que nos permitiram a publicação destes dados.

\section{REFERÊNCIAS}

1. Baxby D, Bennett M. Cowpox: a reevaluation of the risks of human cowpox based on new epidemiological information. Archives of Virology 13: 1-12, 1997.

2. Chantrey J, Meyer H, Baxby D, Begon M, Bown KJ, Hazel SM, Jones T, Montgomery WI, Bennett M. Cowpox: reservoir hosts and geographic range. Epidemiology and Infection 122: 455-460, 1999.

3. Damaso CRA, Esposito JJ, Condit RC, Moussatché N. An emergent poxvirus from humans and cattle in Rio de Janeiro State: Cantagalo virus may derive from Brazilian smallpox vaccine. Virology 277: 439-449, 2000.

4. Fagliari JJ, Passipieri M. Relato sobre a ocorrência de pseudovaríola em vacas lactantes e ordenhadores do município de Aparecida do Tabuado-MS. Arquivos do Instituto de Biologia 66:128, 1999.

5. Heilbronner C, Harzic M, Ferchal F, Pothier A, Charara O, Beal G, Bellaiche M, Lesca $\mathrm{C}$, Foucand $\mathrm{P}$. Infection à cowpox virus chez l'enfant. Archives de Pédiatrie 11:335-339, 2004.

6. Lewis-Jones MS, Baxby D, Cefai C, Hart CA. Cowpox can mimic anthrax. British of Journal of Dermatology 129:625-627, 1993.

7. Lewis-Jones S. Zoonotic poxvirus infections in humans. Current Opinion in Infections Disease 82:253-259, 2004.

8. Lobato ZIP, Trindade GS, Frois MCM, Ribeiro EBT, Dias GRC, Teixeira BM, Lima FA, Almeida GMF, Kroon EG. Surto de varíola bovina causada pelo vírus Vaccinia na região da Zona da Mata Mineira. Arquivo Brasileiro de Medicina Veterinária e Zootecnia 57: 423-429, 2005.

9. Nagasse-Shugara, TK, Kisielius JJ, Ueda-Ito M, Curti SP, Figueiredo CA, Cruz AS, Silva MMJ, Ramos CH, Silva MCC, Sakurai T, Salles-Gomes LF. Human vaccinia-like virus outbreaks in São Paulo and Goiás States, Brazil: virus detection, isolation and identification. Revista do Instituto de Medicina Tropical de São Paulo 46: 315-322, 2004.

10. Postma BH, Diepersloot RJA, Niessen GJCM, Droog RP. Cowpox-virus-like infection associated with rat bite. Lancet 337: 733-734, 1991. 
11. Rajan N, Carmichael AJ, McCarron BM. Human cowpox: presentation and investigation in an era of bioterrorism. Journal Infection 51:167-169, 2005.

12. Schatzmayr HG, Lemos ERS, Mazur C, Schubach A, Majerowicz S, Rozental T, Schubach TMP, Bustamante MC, Bart OM. Detection of poxvirus in cattle associated with human cases in the State of Rio de Janeiro: preliminary report. Memórias do Instituto Oswaldo Cruz 95: 625-627, 2000.

13. Schatzmaryr HG, Romijin PC, Barreto DF, Silva EE, Farias Filho JC, Tavares AFA, Barth OM. An outbreak of vesicopustilar disease in humans and dairy cattle in the state of Rio de Janeiro. Virus Revised Research 10:61-63, 2005.

14. Schupp P, Pfeffer M, Meyer H, Burck G, Kömel K, Neumann C. Cowpox vírus in a 12 -year-old boy: rapid identification by an orthopoxvirus-specific polymerase chain reaction. British of Journal of Dermatology 145:146-150, 2001.

15. Silva RA, Moraes LT. Nota sobre a ocorrência da variola bovina no Estado do Rio de Janeiro. $1^{\circ}$ Estudo da doença no Município de Três Rios. Veterinária Rio de Janeiro 14:31-35, 1961.

16. Trindade GS, Fonseca FG, Marques JT, Nogueira ML, Mendes LC, Borges AS, Peiró JR, Pituco EM, Bonjardim CA, Ferreira PC, Kronn EG. Araçatuba virus: a vaccinia-like vírus associated with infection in humans and cattle. Emerging Infectious Diseases 9: 155-160, 2003.

17. Wolfs TFW, Wagenaar JA, Neisters HGM, Osterhaus ADME. Rat-to-human transmission of cowpox infection. Emerging Infectious Disease. [cited 2008 March 5]. Available from: URL: http://www.cdc.gov/ncidod/EID/vol8no12/02-0089.htm, 2002. 